\title{
What has time to do with risk? A preliminary communication
}

\author{
ROBYN PARKIN*
}

\begin{abstract}
The reliability of risk techniques is of concern to academics and practitioners: if techniques are not reliable in their design, they cannot give reliable results.

This paper briefly discusses risk velocity, which is a way of providing specificity to an understanding of risk through applying time as a lens. The research is a preliminary communication from initial Masters research. Risk velocity has been identified in the limited literature as being divided into three sections: time to cause, time to impact, and time to recover; each of which can assist an organisation to better understand their risk landscape and how risks link with business continuity planning.
\end{abstract}

However, risk velocity has been the subject of limited research to validate the concept and reliability in practice, suggesting this a 'white space' meriting investigation (Cherry, 2010).

Keywords: risk, risk velocity, risk management, time, white spaces

Risk is defined in ISO31000 as the "effect of uncertainty on objectives", and one aspect of uncertainty is the speed with which causal factors may result in an event with consequences to a business' objectives. Traditionally, risk management has concerned itself with likelihood and consequences (Standards New Zealand, 2018) but less so the speed of change in a system. Experience suggests that this area of uncertainty may not be well understood by practitioners and decision makers.

Going down to the video shop and getting out a movie to enjoy used to be a special Friday night treat in the 80s and 90s. In New Zealand, the video and DVD rental chain, United Video, used to have over 100 stores; now there are just seven (Gates, 2021). The arrival of online streaming services sent many of those shops out of business, and the Covid-19 pandemic has caused many more to close (Gates, 2021). When the chain was looking at risks during their heyday, it was unlikely that they foresaw, on the horizon, the rapid societal shift away from DVDs to streaming because it was too far away (Institute of Risk Management, n.d.).

Cherry (2010) uses the image of "white spaces" as a metaphor for uncertainties (unknowns) in a discipline. She discusses the "wicked problems" and "juicy opportunities" that practical and applied research contributes, where there are complex practices to manage and where the

\footnotetext{
* Robyn Parkin is a Chartered Member of the Institution of Occupational Safety and Health and a Certified Professional Member of the New Zealand Institute of Safety Management.

She is studying towards a Master of Health (Workplace Health and Safety) at Victoria University of Wellington.
}

Email: robyn.parkin@ymail.com 
practitioner is "making choices - which might be conscious or not - about what to do and how to do it" (Cherry, 2010, p. 14). One of the "white spaces" in risk management is a lack of research into how the velocity of risk is represented to decision makers: a lack of understanding of the influence of time on risk increases uncertainty,

\section{What has time to do with risk?}

Risk velocity - the speed that a risk acts - is an emerging concept in enterprise risk management that may reduce uncertainty concerning how quickly changes may occur in business. However, there is a lack of research in the concept of risk velocity, and whether it is more than a qualitative judgement on the part of a risk assessor.

The limited literature consists of a small number of mentions in practitioner publications (Davis \& Lukomnik, 2010; Dunning, 2014; Mandel, 2009; Ossinger, 2019; Ramamoorti et al., 2017; Ramamoorti et al., 2019; Sobel, 2010; Tattam \& Esteban, 2013), one Masters' thesis (Chaparro, 2013) and a very short mention in a report by the Committee of Sponsoring Organizations (COSO) of the Treadway commission (2016), that identifies how the concept of risk velocity may be of use in managing enterprise-level risks. Some peer-reviewed articles applied the risk velocity concept to the share market following the impact of the Covid-19 pandemic (AlAli, 2020; Winck, 2020), and in a wider consideration of overall risk management activities in operational banking (Grimwade, 2019). Anecdotal evidence suggests that risk velocity is also used by fire engineers as a time/temperature curve to assess the time from ignition to full fire involvement and then decay (C. Peace, personal communication, 2021).

Risk velocity is a concept that exists in the white spaces of occupational health and safety research; it is an area that has not been sufficiently academically researched, or tested in application by practitioners. Although COSO (2016) identifies that it could be of use in enterprise risk management, the concept of risk velocity could be used more widely in considering system-wide risks, including those with occupational health and safety-related consequences.

Velocity is not a discussion of probability; it is concerned with changes over time. The practitioner publications and thesis referenced above that have carried out the furthest thinking in this area suggest that there are three parts: time to cause, time to impact, and time to recover (Chaparro, 2013; Sobel, 2010; Tattam \& Esteban, 2013), as shown in Table 1.

Table 1: Risk velocity definitions

\begin{tabular}{|l|l|l|}
\hline Term & Definition \\
\hline $\begin{array}{l}\text { Risk velocity time to } \\
\text { cause }\end{array}$ & The time that a risk event takes to occur \\
\hline $\begin{array}{l}\text { Risk velocity time to } \\
\text { impact }\end{array}$ & $\begin{array}{l}\text { The time taken for a risk to cause an identifiable impact on an } \\
\text { activity or business objectives }\end{array}$ \\
\hline $\begin{array}{l}\text { Risk velocity time to } \\
\text { recover }\end{array}$ & $\begin{array}{l}\text { The time required for an activity or business to recover from } \\
\text { the impact of a risk }\end{array}$ \\
\hline
\end{tabular}


These three parts of risk velocity encourage a wider understanding of risk, helping to clarify some of the "white spaces" around decisions on how to manage risks.

Analysis using risk velocity may help decision-makers by providing a clearer view of the risk landscape, which is not limited to risk exposures within a business. The business context is important as well (International Standards Organisation, 2018). For example:

- Would White Island Tours have chosen to continue visits to Whakaari when the volcano was at Volcanic Alert Level 2 if they had considered the risk velocity of a volcano? The time to impact was very fast, even instantaneous, and time to recover very long, or not at all (Radio NZ, 2020).

- A busy port or manufacturing site will have many hundreds of mobile plant movements in a day. The inherent risk of interaction with pedestrians is high; a mobile plant-pedestrian accident would be expected within days or weeks if there were no controls in place (short risk velocity time to cause). Risk velocity time to impact would be nearly instantaneous as the mobile plant collided with a person, and risk velocity time to recover is likely to be months or years, for the person to recover from their injuries, and the same for the business to recover from any external investigation by a regulator and the reputational damage that may result (see, for example, “Worksafe NZ v Toll Networks NZ Ltd" 2018).

An example of how risk velocity information might be displayed is shown in Table 2 . These may seem unlikely table-mates but risk velocity is their commonality.

Table 2: Example risk velocity table

\begin{tabular}{|l|l|l|l|}
\hline & $\begin{array}{l}\text { Risk velocity } \\
\text { time to cause } \\
\text { (RV TTC) }\end{array}$ & $\begin{array}{l}\text { Risk velocity time to } \\
\text { impact (RV TTI) }\end{array}$ & $\begin{array}{l}\text { Risk velocity time } \\
\text { to recover (RV } \\
\text { TTR) }\end{array}$ \\
\hline $\begin{array}{l}\text { Mobile plant-pedestrian } \\
\text { interaction }\end{array}$ & Medium slow & Very fast & $\begin{array}{l}\text { Very long/unable } \\
\text { to recover }\end{array}$ \\
\hline $\begin{array}{l}\text { Implication of streaming } \\
\text { services on rental DVD } \\
\text { market }\end{array}$ & Very slow & Very long & Unable to recover \\
\hline Whakaari White Island & Very slow & Very fast & Very slow \\
\hline
\end{tabular}

Applying the three parts of risk velocity shows how these time factors could influence risk management. Consideration of time might then make more evident the need for planning. For example, a risk with a very short time to impact would be managed differently from one that takes a long time before its impact is fully felt (Ho \& $\mathrm{Li}, 2019)$. Risk velocity might both support better risk management and strengthen existing links between risk management and horizon scanning for events that may impact on business objectives.

\section{What does risk have to do with time?}

The author's work in the white spaces of risk management as a long-term practitioner and early-career researcher has identified that the impact of time on risk has not been adequately addressed in the risk management literature and research. 
Risks and their controls are affected by time: how long the risk takes to occur (time to cause), the period of time before its impact is felt (time to impact), and the time to recover from a risk. An understanding of risk velocity in a business can help reduce uncertainty and give a better understanding of how the velocity of each risk exposure may impact on business objectives.

This early work suggests the need for further research into risk velocity in order to explore how it can be used by practitioners to better inform decision makers and help integrate risk management activities, including occupational health and safety, into business management. This work is underway, and will be reported when completed.

\section{References}

AlAli, M. S. (2020). Risk Velocity and Financial Markets Performance: Measuring the Early Effect of COVID-19 Pandemic on Major Stock Markets Performance. International Journal of Economics and Financial Research, 6(4), 76-82. https://doi.org/10.32861/ijefr.64.76.81

Chaparro, M. R. (2013). A new dimension to risk assessment. Centre for Mathematical Sciences. Lund University. https://lup.lub.lu.se/studentpapers/record/4330718/file/4330725.pdf

Cherry, N. (2010). Doing Qualitative Research in the White Spaces. In J. Higgs, N. Cherry, R. Macklin, \& R. Ajjawi (Eds.), Researching Practice: A discourse on qualitative methodologies (pp. 9-17). Sense Publishers.

Committee of Sponsoring Organizations of the Treadway Commission. (2016). Enterprise Risk Management: aligning risk with strategy and performance. https://www.coso.org/Documents/COSO-ERM-draft-Post-Exposure-Version.pdf

Davis, S., \& Lukomnik, J. (2010). Risk velocity, the unknown dimension in ERM. Compliance Week, 7(72), 56-57

Dunning, M. (2014). Organizations assess velocity of risks: Approach adds details to ERM process. Business insurance, 48(11), 3-3.25

Gates, C. (2021, April 25). United they stand: the people behind our last video stores. Stuff. https://www.stuff.co.nz/entertainment/film/124931567/united-they-stand-the-people-behindour-last-video-stores

Grimwade, M. (2019). Ten laws of operational risk. Journal of Operational Risk, 15(3).

Ho, J., \& Li, T. W. (2019). Next steps in your enterprise risk management journey: Organisations will need to ensure that their ERM roadmap is tailored to the individual needs and context of their business. The Business Times. https://www.businesstimes.com.sg/companies-markets/next-steps-in-your-enterprise-riskmanagement-journey

Institute of Risk Management. (n.d.). Horizon Scanning: A Practitioner's Guide. https://www.theirm.org/media/7423/horizon-scanning_final2-1.pdf 
International Standards Organization. (2018). ISO 31000:2018. Risk management-guidelines. https://www.iso.org/obp/ui\#iso:std:iso:31000:ed-2:v1:en

Mandel, C. (2009). VoR or Velocity of Risk. Risk \& Insurance, 20(10), 16.

Ossinger, J. (2019). Risk Striking Faster Than Ever Has Principal Touting Hedges. Bloomberg. https://www.bloomberg.com/

Radio NZ. (2020, January 29). Whakaari/White Island eruption: Death toll rises to 21. Author. https://www.rnz.co.nz/news/national/408425/whakaari-white-island-eruption-death-toll-rises$\underline{\text { to- } 21}$

Ramamoorti, S., Baskin, D. L., Jr., Epstein, B. J., \& Wanserski, J. (2017). Managing risk at the speed of change: a new risk vocabulary and a call to the profession. The CPA journal, 87(6), 6-9.

Ramamoorti, S., Wanserski, J. H., \& Stover, R. (2019). The Velocity of Risk. The Internal Auditor, 76(2), 20-21.

Sobel, P. (2010). Graduate-level risk assessment: auditors need to think beyond impact and likelihood to assess risks in today's complex business world. The Internal Auditor, 67(3), 61.

Standards New Zealand. (2018). AS/NZS ISO45001: 2018 Occupational Health and Safety Management Systems - requirements with guidance for use. https://www.standards.govt.nz/

Tattam, D., \& Esteban, A. (2013). Risk velocity - the third dimension of risk? Keeping good companies, 65(3), 146-149.

Winck, B. (2020). A top market expert details how 6 factors that fuelled the coronavirus crash will shape the stock market's recovery. Business Insider. https://www.businessinsider.com.au/stock-market-outlook-risks-coronavirus-selling-shaperally-expert-economy-2020-6? $\mathrm{r}=\mathrm{US} \& \mathrm{IR}=\mathrm{T}$

Worksafe NZ v Toll Networks NZ Ltd, Paul J, (District Court 2018). https://www.districtcourts.govt.nz 